Marquette University

e-Publications@Marquette

College of Nursing Faculty Research and

Publications

Nursing, College of

$5-1-2014$

\title{
Cohort Efficacy Study of Natural Family Planning among Perimenopause Age Women
}

Richard Fehring

Marquette University, richard.fehring@marquette.edu

Qiyan $\mathrm{Mu}$

Marquette University

Accepted version. Journal of Obstetric, Gynecologic \& Neonatal Nursing, Vo. 43, No. 3 (May/June 2014): 351-358. DOI. (C) 2014 Wiley. Used with permission. 
Abstract

3 Objective: The purpose of this study was to determine the efficacy of using natural family

4 planning (NFP) methods to avoid unintended pregnancy among women of perimenopause age

$5 \quad$ (i.e., $40-55$ years old).

6 Design: A secondary analysis of subset data from two prospective observational cohort studies.

7 Setting: A university based in-person and online NFP service program.

8 Participants: One hundred and sixty couples who utilized either a website or an in-person NFP

9 service to learn how to avoid pregnancy from January 2001 to November 2012.

10 Methods: A prospective 12-month effectiveness study among 160 women (between the ages of

1140 and 55) who used NFP to avoid pregnancy. The women utilized either a hormonal fertility

12 monitor, or cervical mucus monitoring or both to estimate the fertile phase of their menstrual

13 cycle. Survival analysis was used to determine the pregnancy rate over 12 months of use.

14 Results: There were a total of 5 unintended pregnancies among the participants. The typical use

15 pregnancy rate was 6 per 100 women over 12 months. The monitor alone participants $(\mathrm{n}=35)$

16 had a 12-month pregnancy rate of 3 , the $(n=73)$ who used mucus alone had a pregnancy rate of 4 ,

17 and the participants $(n=42)$ who used the fertility monitor plus mucus had a pregnancy rate of 6.

18 Conclusion: NFP methods can be effective for older women to avoid an unintended pregnancy

19 with correct use and adequate instructions. The pregnancy rate most likely was affected by

20 diminished fertility and motivation to limit family size.

21 Key words: natural family planning; fertility monitoring; peri-menopause 
24 Call outs:

$25 \# 1$.

26 Little is known about the efficacy of natural family planning methods among perimenopause age

27 women.

$28 \# 2$.

29 There was a typical use unintended pregnancy rate of 4 per 100 women over 12 months of use 30 among perimenopausal age women using the Marquette Model of NFP.

$31 \# 3$.

32 Effectiveness of NFP methods among perimenopause age women is most likely confounded by 33 reduced fertility and a high motivation to avoid pregnancy.

Use of natural family planning (NFP) by perimenopausal women (i.e., those who are 40

37 years age and above) can be a challenge. NFP during the perimenopause is difficult because the

38 menstrual cycle becomes more variable and the natural signs of fertility are difficult to track

39 (Brodin, Bergh, Berglund, Hadziosmanovic \& Holte, 2008; Fehring \& Schneider, 2006; Treloar,

40 Boyton, Behn, \& Brown, 1967). Furthermore, the peri-menopause is a time of a woman's and

41 couples' life when they have completed their family size. There is also the greater chance of

42 having a child with congenital abnormalities such as downs syndrome during the later 
43 reproductive ages (Beemsterboer, Homburg, Gorter, Schats, Hompes, \& Lambalk, 2006;

44 Schmidt, Sobotka, Bentzen, \& Andersen, 2012). Although fertility of women decreases with age

45 there still is a concern with unintended pregnancies especially among women with apparent

46 ovulatory menstrual cycles.

47 Little is known about use of NFP during the peri-menopause transition to infertility.

48 Conceptually, NFP is knowledge of and the ability to track the fertile phase of the menstrual

49 cycle with natural indicators of fertility (Fehring, Kitchen, \& Shivanandan, 2009). With

50 knowledge of the fertile phase a couple can modify their behaviors to either avoid or achieve

51 pregnancy. The common natural indicators of fertility used in methods of NFP are changes basal

52 body temperature (BBT), cervical mucus changes, and urinary reproductive hormones. A

53 significant elevation from baseline of BBT occurs due to the rise in progesterone after ovulation,

54 cervical mucus becomes more profuse, stretchy, clear, and slippery due to the rise in estrogen

55 from the dominant follicle/egg complex, and hand held electronic fertility monitors are available

56 to track rising levels of estrogen from a dominant follicle and threshold levels of luteinizing

57 hormone (LH) that occurs about 24-36 hours before ovulation in urine samples. These natural

58 signs of fertility can be used alone or in combination to track the beginning, peak and end of the

59 fertile window and the variability from menstrual cycle to menstrual cycle (Fehring, Kitchen, \&

60 Shivanandan, 2009).

Brown (2010) mentioned that the perimenopause transition to infertility is almost like the

62 reverse of the experience of menstrual cycle initiation and variability with adolescents.

63 Physiologically fertility decreases and the menstrual cycle becomes more variable due to a

64 significant decrease in egg/follicles in the ovaries, aging of the male and female gametes,

65 anovulatory menstrual cycles, large increases in follicle stimulating hormone (FSH), and 
decreases in antimularian hormones (AMH) (Brodin, Bergh, Berglund, Hadziosmanovic, \& Holte, 2008; Hale, Hughes, Burger, Robertson, \& Fraser, 2009; Speroff \& Fritz, 2005; Van Zonneveld et al., 2003). Studies based on the Natural Survey of Family Growth (NSFG) have shown that the prevalence of infertility after 12 months of attempting to achieve a pregnancy is only $6.7 \%$ among those $20-24$ years of age, but increases to $16.1 \%$ among women $30-34$ years and 22.9\% among women 35-39 years (Chandra, Martinez, Mosher, Abma, \& Jones, 2005). The World Health Organization (WHO) (1990) published a report on the peri-menstrual transition, diminishing fertility, and the use of family planning. The report indicated that $50 \%$ of women over forty are potentially fertile but the risk of pregnancy for women $40-44$ is about $10 \%$, around $2 \%$ for women 45-49, and not zero for women over the age of 50 (Metcalf, 1979; Gray, 1997). The severe decrease in fertility after the age of 45 was demonstrated by researchers that observed records of all Israeli women who delivered naturally after the age of 45 and found only 209 women out of 104,659 who delivered a baby were 45 years or older or i.e., $0.2 \%$ of the total (Laufer, Simon, Samueloff, Yaffe, Milwidsky, and Gielchinsky, 2009). The WHO report recommended contraception until menopause is established and mentioned that due to the irregular menses and amenorrhea that use of NFP would be impractical during the perimenopause (1990). However, the report also mentioned that among women who have been amenorrheic for one year, approximately $2 \%$ of them would experience a subsequent ovulation. Hence there is still a concern for potential pregnancy and a recommendation for contraception for one-year post menopause.

In reviewing the literature there are no studies that specify the efficacy of NFP among perimenopausal women. A study was conducted with 36 users of the symptom-thermal method of NFP (i.e., a combination of self-monitoring of mucus changes and BBT) who were between 
the ages of 45 and 53 (Flynn, James, Collins, \& Royston, 1991) and found that $33 \%$ of the women were potentially fertile and that $61 \%$ of the 177 menstrual cycles charted were potentially fertile. They did not determine efficacy of the method to avoid pregnancy.

Professional nurses at Marquette University have developed a method of NFP that includes an electronic hormonal fertility monitor (EHFM) that measures metabolites of estrogen and luteinizing hormone $(\mathrm{LH})$ in the urine and provides an estimate of the fertile window (Fehring, Schneider, \& Raviele, 2007). Subsequent efficacy and effectiveness studies on this new method called the Marquette Model (MM) of NFP for couples wishing to avoid pregnancy ranged from 0-3 unintended pregnancies per 100 users over 12 months of use with correct use and 8-13 with typical use (Fehring, Schneider, \& Barron, 2008; Fehring, Schneider, Barron, \& Raviele, 2009; Fehring, Schneider, \& Raviele, 2011; Bouchard, Schneider, \& Fehring, 2013; Fehring, Schneider, Raviele, Rodriguez, \& Pruszynski, 2013). The purpose of this report is to provide evidence for efficacy in the use of the MM of NFP for avoiding pregnancy among women 40 to 55 years of age. The specific research objectives were to determine the correct use and the typical use unintended pregnancy rate among women age 40 to 55 years of age using the MM of NFP. A secondary objective was to determine typical use pregnancy rates among subpopulations of women 40 to 55 years of age using different forms of the MM, i.e., cervical mucus monitoring (CMM) plus fertility algorithm, EHFM with fertility algorithm, and a combination of CMM and EHFM plus fertility algorithm.

\section{Methods}

\section{Research Design}

This study was a secondary analysis of data collected from two 12 month prospective efficacy studies of the new MM of NFP (Fehring, Schneider, \& Raviele, 2007; Fehring, 
112 Schneider, \& Raviele, 2011) and of new data collected prospectively since completion of the

1132011 study. Data from each study was generated from two university based NFP programs i.e.,

114 an in-person NFP service program and an online NFP program. Both programs taught women

115 and couples how to use either a cervical mucus based method of NFP, a hormonal fertility

116 monitoring method of NFP, or both to avoid or achieve pregnancy. The in-person program was

117 initiated in 2001 and the online program in 2008. There is an ongoing research effort with the

118 online program to determine the efficacy of the MM NFP (to help couples either achieve or

119 avoid pregnancy) and use by sub-populations, e.g., postpartum breastfeeding women (Bouchard,

120 Schneider, \& Fehring, 2013), women wishing to achieve pregnancy (Mu \& Fehring, 2014) and

121 now efficacy to avoid pregnancy among women between the age of 40 and 55.

\section{Setting and Subjects}

We were able to obtain 160 women who were between the age of 40 and 55 and who

124 sought to learn the MM of NFP from either an in-person nurse managed NFP service program

$125(n=80)$ or an online nurse managed NFP service program $(n=80)$ from January 2001 to

126 November 2012. The participants learned about the online program or in person program

127 through word of mouth, online blogs, and/or NFP e-mail list services. The participants in the in

128 person program sought and received education and counseling in the MM of NFP from

129 professional nurse NFP teachers in private offices in the College of Nursing. The online

130 participants $(n=115)$ received self-knowledge of the MM NFP method by reading the online

131 materials and charting their menstrual cycles in the online automatic charting system.

132 The age range of 40-55 was chosen as an inclusion criteria since fertility decreases

133 significantly by the age of 40, many couples have completed their family size, and because 40 is

134 the traditional age that NFP systems start to classify women as in the perimenopausal 
135 reproductive category (Howard \& Stanford, 1999). Pregnancy after the age of 55 is extremely

136

137

138

139

140

141

142

143

144

145

146 147 Canada.

148

149

150

151

152

153

154

155

156

157

rare, in fact, the national survey of family growth (NSFG) only calculates pregnancy rates up to

the age of 44 (Trussell, 2011). The participants were at least three months past cessation of

breastfeeding or discontinuation of hormonal contraception. We sought to have a minimum of

100 participants in order to apply and obtain an adequate survival analysis based on 100 women

users over 12 months of use with a standard error of approximately of .05 or less.

Both the in person and online versions of the NFP efficacy studies were approved by the university office of research compliance. All participants completed demographic registrations forms and signed consent for this study either in person during a teaching session or to access the online program. The 160 participants that met the age inclusion criteria were all women that have registered and used either the in-person or online system, i.e., they were not selected from a group of participants. Participants in these two programs came from over 47 states and

\section{Procedures}

All participants charted their menstrual cycles, their estimate days of fertility, and days of intercourse on either a paper chart (first study) or an online charting system (second study).

Participants, who used the cervical mucus method, observed their cervical mucus on a daily basis and rated their observations as Low, High or Peak type mucus based on a provided pictorial (online or in-person) diagram. The women who used the hormonal fertility monitor also rated their fertility as Low, High, and Peak based on the information provided by the electronic hormonal fertility monitor. The fertility monitor (the Clearblue Easy Fertility Monitor) provides a Low fertility reading until it detects a significant rise in urinary estrogen from base line to provide a High reading, and the Luteinizing hormone $(L H)$ threshold to provide a Peak reading 
158 (May, 2001). When using both cervical mucus and the fertility monitor they were instructed to

159 wait for both the monitor and mucus to establish their daily fertility. All women used a fertility algorithm along with their fertility indicators, i.e., fertility begins on day 6 of the menstrual cycle and lasts three full days past the last peak reading of either the mucus or monitor. After 6 cycles of charting, fertility begins with the earliest Peak recording from the previous 6 cycles minus 6 days. All participants indicated their intention to avoid or achieve pregnancy on each menstrual cycle chart before beginning the charting for that menstrual cycle. One page protocols on the MM method and use with special reproductive categories (i.e., postpartum breastfeeding) can be found at http://nfp.marquette.edu. This web site also has one page Quickstart instructions that could be used for replication and visual pictures of the three levels of cervical mucus observations.

\section{Measurement of Outcomes}

All pregnancies were reviewed by two professional nurse NFP teachers with use of a pregnancy evaluation form that included feedback by the user and by assessing the menstrual cycle chart in which the pregnancy occurred. The pregnancy evaluation form was developed by Gray and Kambic (1984) for NFP service programs as an aid for assessing and determining pregnancy rates. Two professional nurses, trained and certified in NFP, reviewed all pregnancies and all pregnancy menstrual cycles, and classified the pregnancy as either a correct use unintended pregnancy or an inconsistent or incorrect use pregnancy - with $100 \%$ agreement. To determine the correct use pregnancy rates only menstrual cycle charts with correct use (i.e., no intercourse during the estimated fertile phase) were included in the analysis. Typical use pregnancy rates included menstrual cycles with correct use and incorrect or inconsistent use. Of 
180 the 160 women, we were able to determine correct use pregnancy rates among the 80 women 181 who used the online NFP program.

Data from the demographic forms and the paper and online menstrual cycle charts were

183

184

\section{Demographics}

\section{Analysis of Data} total cycles.

Results

Analysis of pregnancy rates followed the recommended instructions by Lamprecht and Trussell (1997). Survival analysis (Kaplan Meier) was used to determine both correct use and typical use pregnancies rates with the statistical package for social sciences (SPSS Version 9) software. Analysis by research objectives were as follows: 1) to determine the correct use pregnancy rates only menstrual cycles with correct were used in the analysis, 2) to determine total or typical pregnancy rates the total of correct use, inconsistent use, and incorrect use menstrual cycles were used in the analysis, and 3) pregnancy rates with the subpopulation of CMM users, EHFM users, and combination of CMM plus EHFM use (plus a fertility algorithm) was based on correct use and incorrect use menstrual cycles. Cumulative pregnancy rates were calculated with two different censoring variables: correct use (also referred to as perfect use) and

\section{Results}


The mean age of the 160 female participants was $41.2(S D=2.4)$ with an age range of

203

204 40-54 years. Fifteen of the participants were 45 years of age or older. The participants were married a mean of 13.3 years $(S D=7.3)$ and a range of $1-32$ years. They had a mean of $5.2(S D$ $=2.6$; range $0-13)$ pregnancies and a mean 4.2 live children $(S D=2.2$; range $0-9)$. All participants were married, 94\% were of the Catholic faith, and79\% were Euro-Americans; $9 \%$ were Hispanic American. Thirty-five of the participants used only the fertility monitor, 73 used only cervical mucus, and 52 used both mucus and monitor to estimate the fertile phase of the menstrual cycle. They produced 1,221 menstrual cycles of data, 452 of which were with correct use and 289 with incorrect or inconsistent use.

\section{Unintended pregnancy rates}

Research Objective One -- correct use pregnancy rate: We were able to determine the correct use pregnancy for those $(n=79)$ participants who used the online system to learn and chart the Marquette Model of NFP. There was only 1 correct use unintended pregnancy which yielded a survival pregnancy rate of 1.5 pregnancies per 100 users over 12 months of use. Research Objective Two -- total or typical pregnancy rate: There were a total of 5 unintended pregnancies for all participants $(n=160)$ that produced a typical unintended pregnancy rate of 6 per 100 users (i.e., 94\% survival) over 12 months of use (See Table 1 for pregnancy rates by cycles of use).

Objective Three -- subgroup pregnancy rates: There was one unintended pregnancy among the participants $(n=35)$ using only the EHFM plus fertility algorithm (with a survival pregnancy rate of 3 per 100 women over 12 months of use), 2 pregnancies with the $(n=73)$ CMM only participants (with a survival analysis of 4 pregnancies per 100 users over 12 months of use), and 2 unintended pregnancies among the $(n=52)$ participants who used both monitor 
225 and mucus as fertility indicators (with a survival pregnancy rate of 6 per 100 users over 12 226 months of use) (See Table 2).

The results of this report indicate that use of the MM of NFP among older women (i.e., age 40-55) can be an effective means of avoiding unintended pregnancy especially with correct use and consistently following the instructions to avoid intercourse during the estimated fertile phase of the menstrual cycle. Our report provided a pregnancy rate of 6 among the older women users (between the ages of 40-54 years) of either cervical mucus only method, mucus plus fertility monitor method, or a combination of mucus plus fertility monitor method of NFP and a correct use rate of only 1.5. This rate compares with unintended pregnancy rates of our previous

235 NFP efficacy studies of 7-16 typical use unintended pregnancies per 100 women over 12 months 236 of use and 0-3 correct use pregnancies among younger women between the ages of 18-42 years 237 (Fehring, Schneider, Raviele, \& Barron, 2007; Fehring, Schneider, \& Barron, 2008; Fehring, 238 Schneider, Barron, \& Raviele, 2009; Fehring et al., 2011; Fehring, et al., 2013) and among 239 women using our special postpartum protocol to avoid pregnancy (Bouchard, Fehring, \& 240 Schneider, 2013). These unintended pregnancy rates also are within the range of efficacy of 241 other methods of NFP, for example, a simplified mucus only method and a standard day calendar 242 method, and in particular the ovulation method (World Health Organization, 1981; Arévalo, 243 Jennings, \& Sinai, 2002; Arévalo, Jennings, Nikula, \& Sinai, 2004; Frank-Herrmann, Et al., $2442007 ;$ ). Furthermore, the unintended pregnancy rate is comparable to the 8-9 per 100 women 245 who use hormonal birth control (Trussell, 2011). 
248

249

250

251

252

253

254

44 years. Three of the unintended pregnancies were within the first menstrual cycle post-partum among the younger women in the data set. There is an obvious bias in this study towards younger women in the 40-55 age group, however, this bias is toward more fertile women participants. Furthermore, all of the participants had what appeared to be ovulatory menstrual cycles based on the estimated day of ovulation and normal looking phases of the menstrual cycle, i.e., follicular and luteal phase lengths. How fertile these 15 post 45 -year-old women are remains to be determined, as indicated by the Israeli study of older women, the pregnancy rate is only .2\% (Laufer et. al., 2009). An obvious limitation of this study is the rather homogenous nature of the participants, being mostly white, educated and middle class. So too, this study had a relatively small number of participants. Finally, it is not known how much the reduction in fertility among these women contributed to the results.

A recent study comparing the efficacy of using the EHFM versus CMM showed that the EHFM method was more effective in helping women avoid unintended pregnancy (Fehring, et al., 2013). In the current study, we also found that there was a lower pregnancy rate among our study participants that were only using the EHFM with a fertility algorithm to estimate the fertile phase. The lower rate might be due to the more objective and accurate nature of hormonal monitoring with the electronic fertility monitor than the more subjective method of CMM. Furthermore, the highest unintended pregnancy rate in this study was among the women who used a combination of EHFM and CMM. The higher pregnancy rate with the combination methods might be because the NFP method is too complex, is difficult to use with consistency, and the multiple indicators lengthens the required abstinence. Length of required abstinence with NFP methods correlates with taking chances during the long fertile phase and as a result, higher unintended pregnancy rates (Fehring, 2009). These results should be taken with caution 
271 as they are not a result of a randomized comparison study and there needs to be many more

272 participants with each method (i.e., approximately 500 participants for each method) in order to

273 have enough statistical power to analyze statistical differences in unintended pregnancy rates.

274 The implication from a practice standpoint is that older women who are still ovulating

275 and wish to use natural methods of family planning (and in particular the MM) can do so with

276 confidence of its efficacy when used with correct use. So too, health professionals could

277 recommend these methods for older women, especially those who might have health

278 considerations for use of hormonal methods of family planning or who wish to use natural

279 methods of family planning to avoid health risks or for religious reasons. However, there is the

280 question as to how much the effectiveness of these NFP methods are due to reduced fertility

281 among older women. A clinical implication is that women over 45 could be informed that their

282 fertility is reduced to a level of about $2 \%$ or less, about the same as correct use of the male

283 condom and better than typical use of hormonal contraception (i.e., 7-9 unintended pregnancies

284 with use of the hormonal pill). They can also be informed that there are ways of monitoring their

285 fertile phase with guidance from competent professional nurse NFP teachers until menstrual

286 cycle variability indicates infertility. We recommend that woman (especially those with serious

287 reasons to avoid pregnancy) utilize professional nurses who have completed NFP teacher

288 training programs that meet established standards (Fehring, 2004).

Another factor that might have influenced low unintended pregnancy rates in this study is

290 motivation. Motivation in avoiding pregnancy is important for NFP efficacy as was recently

291 determine with the Marquette Model of NFP (Fehring, Schneider, Barron, \& Pruszynski, 2013).

292 Assessing motivation to avoid (whether using NFP or any other behavioral methods of family

293 planning) is important. Most couples and women who are older and who have completed their 
294 family size usually have high motivation. Rice, Lanctót, and Garcia-Devesa (1981) discovered 295 that couples who had limited their family size had a pregnancy rate of $4.5 \%$ with use of NFP 296 compared with a pregnancy rate of $15 \%$ among couples who were still spacing their children.

297 Although couples who are limiters are generally older than delayers, the Rice, et al., (19981)

298 study did not determine efficacy of NFP among women in the perimenopause transition.

Future research is recommended with a larger and more diverse sample of women and couples. Comparison of the MM of NFP with other forms of NFP and various combinations of 301 self-indicators of fertility could also be conducted. A high priority would be to determine what 302 indicators would determine when a woman is no longer fertile or that her fertility is so low that

303 there is no concern. There might be some simple algorithms of cycle length and hormonal 304 variability (such as FSH and/or AMH blood levels) that indicate infertility. Significant decreases 305 in $\mathrm{AMH}$, high levels of FSH, and running differences in the length of the menstrual cycle have 306 been found to be somewhat predictive of pending menopause (Ferrell et al., 2007; Freeman, 307 Sammel, Lin \& Gracia, 2012; Santoro, Brockwell, \& Johnston, et al., 2007; Taffe \& Dennerstein, 308 2002). Some of these algorithms are currently being tested (Taffe \& Dennerstein, 2002; Brodin 309 et al., 2008; Hale et al., 2007; Santoro et al., 2007).

We concluded that use of the MM of NFP among older women can be very effective for 311 those who have serious reasons to avoid pregnancy. However, the high efficacy to avoid 312 pregnancy might in large part be a reflection of diminished fertility among older women and 313 their motivation to do so. More research needs to be conducted as to when women can be 314 confident that they are no longer fertile during the perimenopausal transition. 


\section{References}

Arévalo, M., Jennings, V., \& Sinai, I. (2002). Efficacy of a new method of family planning: The Standard Days Method. Contraception, 65(5), 333-338. doi: 10.1016/S0010-7824(02)00288-3

Arévalo, M., V. Jennings, M. Nikula, I. Sinai. 2004. Efficacy of the new TwoDay Method of family planning. Fertility and Sterility, 82:885-892.

Beemsterboer S.N., Homburg R., Gorter N.A., Schats, R., Hompes P.G.A., \& Lambalk, C.B. (2006). The paradox of declining fertility but increasing twinning rates with advancing maternal age. Human Reproduction, 21(6), 1531-1532. doi: 10.1093/humrep/del009

Bouchard, T., Fehring, R. \& Schneider, M. (2013). Efficacy of a new postpartum transition protocol for avoiding pregnancy. Journal of the American Board of Family Medicine, 26(1), 3544. doi: 10.3122/jabfm.2013.01.120126

Brodin T., Bergh T., Berglund, L., Hadziosmanovic, N., \& Holte J. (2008). Menstrual cycle length is an age-independent marker of female fertility: Results from 6271 treatment cycles of in vitro fertilization. Fertility and Sterility, 90(5), 1656-1661. doi: 10.1016/j.fertnstert.2007.09.036

Brown, J. (2010). Types of ovarian activity in women and their significance: The continuum (a reinterpretation of early findings). Human Reproduction Update, 00(0), 1-18. doi:10.1093/humupd/dmq040

Chandra, A., Martinez, G.M., Mosher, W.D., Abma, J.C., \& Jones, J. (2005). Fertility, family planning, and reproductive health of U.S. women. Data from the 2002 National Survey of Family Growth. National Center for Health Statistics. Vital Health Statistics, 23(25). 2005.

Fehring, R. (2004). The future of professional education in natural family planning. Journal of Obstetric, Gynecological \& Neonatal Nursing, 33, 34-43.

Fehring, R. (2009). Efficacy and efficiency in natural family planning services. The Linacre 
Quarterly, 76, 9-24.

Fehring, R., Schneider, M., \& Raviele, K. (2006). Variability in the phases of the menstrual cycle. Journal of Obstetric, Gynecologic \& Neonatal Nursing, 35(3), 376-384. doi: 10.1016/j.fertnstert.2007.10.050.

Fehring, R. J., Schneider, M., Raviele, K., Barron, M. L. (2007). Efficacy of cervical mucus observations plus electronic hormonal fertility monitoring as a method of natural family planning. Journal of Obstetric Gynecologic and Neonatal Nursing, 36(2), 152-160. doi: 10.1111/j.1552-6909.2007.000129.x

Fehring, R. J., Schneider, M., \& Barron, M.L. (2008). Retrospective efficacy of the Marquette Model of natural family planning. The American Journal of Maternal Child Nursing, 33(6), 348-354. doi: 10.1097/01.NMC.0000341254.80426.32.

Fehring, R., Kitchen, S., \& Shivanandan, M. (2009). An Introduction to Natural Family Planning. (T. Notare) Editor. Washington, D.C.: United Sates Conference of Catholic of Catholic Bishops, 27 pgs.

Fehring, R. J., Schneider, M., Raviele, K., \& Barron, M. L. (2009). Cohort comparison of two fertility awareness methods of family planning. Journal of Reproductive Medicine, 54(3), 165170.

Fehring, R. J., Schneider, M., \& Raviele, K. (2011). Pilot evaluation of an Internet-based natural family planning education and service program. Journal of Obstetrics, Gynecology, and Neonatal Nursing, 40(3), 281-291. doi: 10.1111/j.1552-6909.2011.01237.x

Fehring, R. J., Schneider, M., Raviele, K, Rodriguez, D., \& Pruszynski, J. (2013). Randomized comparison of two Internet-supported fertility awareness based methods of family planning. Contraception, 88(1), 24-30. doi: 10.1016/j.contraception.2012.10.010 
Fehring, R. J., Schneider, M., Barron, M.L., \& Pruszynski, J. (2013). Influence of motivation on the effectiveness of natural family planning. The American Journal of Maternal Child Nursing, 38(6): 352-358. doi: 10.1097/NMC.0b013e3182a1ecc0

Ferrell, R. J., Simon, J. A., Pincus, S. M., Rodriguez, G., O’Connor, K. A., Holman, D. J., Weinstein, M. (2007). The length of perimenopausal menstrual cycles increases later and to a greater degree than previously reported. Fertility and Sterility, 86(3). doi: 10.1016/j.fertnstert.2006.01.045

Flynn, A.M., James, P., Collins, W. P., \& Royston, P. (1991). Symptothermal and hormonal markers of potential fertility in climacteric women. American Journal of Obstetrics and Gynecology, 165(6), 1987-1989.

Frank-Herrmann, P., Heil, J., Gnoth, c., Toledo, E., Baur, S., Pyper, C., ... Freundl, G. (2007). The effectiveness of a fertility awareness based method to avoid pregnancy in relation to a couple's sexual behavior during the fertile time: A prospective longitudinal study. Human Reproduction, 22(5), 1310-1319. doi: 10.1093/humrep/dem003

Freeman, E.W., Sammel,M.D., Lin, H. \& Gracia, C.R. (2012). Anti-Mullerian Hormone as a predictor of time to menopause in late reproductive age women. The Journal of Clinical Endocrinology \& Metabolism, 97(5): 1673-1680.

Gray, R. H. (1979). Biological and social interaction in the determination of late fertility. Journal of Biosocial Science, 11(Suppl. S6), 97-115. doi: 10.1017/S0021932000024329

Gray, R.H., \& Kambic, R. (1984). Program evaluation and accountability. In (edited by Lanctot, C.) Natural Family Planning. Development of National Programs. IFFLP: Washington, D.C.

Hale, G. E., Hughes, C. L., Burger, H. G., Robertson, D. M., \& Fraser, I. S. (2009). Atypical estradiol secretion and ovulation patterns caused by luteal out-of-phase (LOOP) events underlying 
irregular ovulatory menstrual cycles in the menopausal transition. Menopause 16(1), 50-59. Doi: 10.1097/gme.0b013e31817ee0c2

Hale, G.E., Zhao, X., Hughes C.L., Burger H.G., Robertson D.M., \& Fraser I.S. Endocrine features of menstrual cycles in middle and late reproductive age and the menopausal transition classified according to the Staging of Reproductive Aging Workshop (STRAW) staging system. Journal of Clinical Endocrine Metabolism, 92(8), 3060-3067. doi: 10.1210/jc.2007-0066

Howard, M.P. \& Stanford, J.B. (1999). Pregnancy probabilities during use of the Creighton model fertility care system. Archives of Family Medicine, 8: 391-402.

Lamprecht, V., \& Trussell, J. (1997). Effectiveness studies on natural methods of natural family planning. Advances in Contraception 13(2-3), 155-165.

Laufer, N., Simon, A., Samueloff, A., Yaffe, H., Milwidsky, A., \& Gielchinsky, Y. (2004). Successful spontaneous pregnancies in women older than 45 years. Fertility and Sterility 81(5), 1328-1332. doi: 10.1016/j.fertnstert.2003.09.056

Mansfield, P.K., Carey, M., Anderson, A., Barsom, S.H., \& Koch, P.B. (2004). Staging the menopausal transition: data from the TREMIN research program on women's health. Women's Health Issues, 14(6), 220-226. doi: 10.1016/j.whi.2004.08.002

Metcalf, M. G. (1979). Incidence of ovulatory cycles in women approaching the menopause. Journal of Biosocial Science, 11, 39-48.

May, K. (2001). Home monitoring with the ClearPlan Easy Fertility Monitor for fertility awareness. The Journal of International Medical Research, 29(Suppl 1), 14A-20A. doi: $10.1177 / 14732300010290 S 103$

Mosher, W.D., \& Jones, J. (2010). Use of contraception in the United States: 1982-2008. Vital and Health Statistics Series 23, Number 29, 1-771. 
Mu, Q., \& Fehring, R J. (2014). Efficacy of achieving pregnancy with fertility focused intercourse. MCN The American Journal of Maternal Child Nursing. 39(1): 35-40. doi: 10.1097/NMC.0b013e3182a76b88

Rice, F. J., Lanctót, C. A., \& Garcia-Devesa, C. (1981). Effectiveness of the sympto-thermal method of natural family planning: an international study. International Journal of Fertility, 26(3), 222-230.

Santoro, N., Brockwell, S., Johnston, J., Crawford, S.L., Gold, E. B., Harlow, S. D., Matthews K. A., Sutton-Tyrrell, K. (2007). Helping midlife women predict the onset of the final menses: SWAN, the Study of Women's Health Across the Nation. Menopause, 14(3), 415-424. doi: 10.1097/gme.0b013e31802cc289

Schmidt, L., Sobotka, T., Bentzen, J. G., \& Andersen, A. N. (2012). Demographic and medical consequences of the postponement of parenthood. Human Reproduction Update, 18(1), 29-43. Doi: 10.1093/humupd/dmr040

Speroff, L, \& Fritz, M.A. (2005). Menopause and the perimenopausal transition. In Clinical Gynecologic Endocrinology and Infertility, (7th ed, pp. 621-688). Philadelphia: Lippincott Williams and Wilkins.

Taffe, J.R., Dennerstein, L. (2002). Menstrual patterns leading to the final menstrual period. Menopause, $9(1), 32-40$.

Treloar, A.E., Boyton, R.E., Behn, B.G., \& Brown, B.W. (1967). Variation of the human menstrual cycle through reproductive life. International Journal of Fertility, 12(1), 77-126.

Trussell, J. (2011). Contraceptive Failure in the United States, Contraception 83, 397-404. doi: 10.1016/j.contraception.2011.01.021 
Van Zonneveld, P., Scheffer, G.J., Broekmans, F.J., Blankenstein, M. A., de Jong, F. H., Looman, C. W., ...te Velde, E. R. (2003). Do cycle disturbances explain the age-related decline of female fertility? Cycle characteristics of women aged over 40 years compared with a reference population of young women. Human Reproduction, 18(3), 495-501. 10.1093/humrep/deg138

World Health Organization. (1981). A prospective multicentre trial of the ovulation method of natural family planning. II. The effectiveness phase. Fertility and Sterility, 36(5), 591-598.

World Health Association. (1994). Research on the menopause in the 1990s: Report of a Scientific Group. Switzerland: Geneva. 
Table 1

Total pregnancy rates of NFP use $(n=160)$ per 100 women over 12 menstrual cycles of use

\begin{tabular}{lllll}
\hline & Preg. & Estimate & Std. Error & Pregnancy rate \\
3 cycles: & 3 & 0.97 & .01 & 3 \\
6 cycles: & 0 & 0.97 & .01 & 3 \\
9 cycles: & 1 & 0.96 & .02 & 4 \\
12 cycles: & 1 & 0.94 & .03 & 6 \\
Total pregnancies & 5 & & & 6 \\
\end{tabular}


Table 2. Twelve cycle typical (total) survival rates in avoiding an unintended pregnancy by NFP method; 1) electronic hormonal fertility monitor (EHFM), 2) cervical mucus monitoring (CMM), and 3) combination of EHFM and CMM.

\begin{tabular}{|c|c|c|c|c|c|}
\hline NFP Method & Number & \# Preg. & Estimate & $\underline{\text { Std. Error }}$ & $\underline{\text { Rate }}$ \\
\hline EHFM & 35 & 1 & 0.97 & 0.03 & 3 \\
\hline CMM & 73 & 2 & 0.92 & 0.06 & 4 \\
\hline $\mathrm{EHFM+CMM}$ & 52 & 2 & 0.94 & 0.04 & 6 \\
\hline
\end{tabular}

